John Carroll University

Carroll Collected

\title{
Coming Alongside Supervisees: Introducing the Skillset of Companioning to Counselor Supervision
}

Rob McKinney

Gonzaga University

Paula Britton

John Carroll University, pbritton@jcu.edu

Follow this and additional works at: https://collected.jcu.edu/fac_bib_2021

Part of the Counselor Education Commons

\section{Recommended Citation}

McKinney, Rob and Britton, Paula, "Coming Alongside Supervisees: Introducing the Skillset of Companioning to Counselor Supervision" (2021). 2021 Faculty Bibliography. 12.

https://collected.jcu.edu/fac_bib_2021/12 


\section{Coming Alongside Supervisees: Introducing the Skillset of Companioning to Counselor Supervision}

Robert Wolfelt (2005) introduced the idea of companioning into the field of grief counseling. Companioning could also be utilized as a skillet within counseling supervision. As supervision is an essential element of counseling, integrating this skillset would be beneficial to the counseling profession. The topic of companioning and its 11 tenets are first explored and then placed within the context of counseling supervision as a useful and valuable skillset for working with supervisees. The skillset is then explored through various existing models of supervision and illustrated through a case study. Finally, implications for supervisors and educators, as well as future research within the counseling profession, are included.

Keywords: companioning, counselor supervision, supervision skill

Counseling supervision is described as an intervention from a senior member of the counseling profession to a junior member (Bernard \& Goodyear, 2014). Supervision helps to ensure the welfare of clients, the professional development of supervisees (Overholser, 
2004), and it can be delivered through various modalities (Anderson, 2002; Bernard, 1997; MacKay \& Brown, 2014; Rønnestad \& Skovholt, 2003). Many techniques and skills have been developed which could be embedded within established supervision models (Carlson \& Erickson, 2001; Gingerich \& Eisengart, 2000; Shurts, 2015). Yet, other skills could be created and utilized to increase the effectiveness of supervision. Robert Wolfelt's (2005) concept of companioning, an idea found in grief counseling and innovatively applied here for the first time to supervision, can offer supervisors a distinctive skillset to engage in during supervision to effectively work with supervisees in a relationally-based way. Therefore, the purpose of this article was to introduce the companioning skillset, to examine companioning through other relevant supervision models, to illuminate the benefits of companioning through a case study, and to discuss implications for professional supervisors, counselor educators, and researchers.

\section{Companioning}

Originating from Wolfelt's (2005) work in grief counseling, this practice can be etymologically understood by examining the root meaning of the word "companioning." Wolfelt noted that companioning's Latin roots are derived from com meaning "with" and pan meaning "bread," so companioning can be equated to the idea of "sitting at a table together, being present to one another, sharing, communing, abiding the fellowship of hospitality" (p. 17). Companioning, therefore, invites professionals to be with clients in a way that is not about assessing and rapidly resolving presenting concerns, but it means to sit with clients in their grief.

While this idea may appear rather simple, companioning is a multifaceted skillset through its 11 tenets. Wolfelt (2005) elucidated that to companion is to be presentoriented and not to be focused on past or future occurrences. Therefore, the skillset of companioning has one focus: this moment. Companioning involves coming alongside another individual and, without taking responsibility to help, lead, or give expert advice, adopting a stance of curiosity. This skillset emphasizes that instead of telling others what to do or what needs done, one asks questions, inquires, and works with others to derive 
possibilities. As individuals companion, they can acknowledge that remaining in one place, or on one topic, and not progressing is a possibility. To companion also means to honor the spirit of the individual, to acknowledge the individual's struggles without judging, and to respect the possible disorder or confusion of the individual's situation. This struggle and disorder can bring about emotional difficulty, and Wolfelt noted that one must be comfortable in silence and be able to utilize it through companioning. Furthermore, not only does the action of companioning clarify a focus for the other individual, but those who utilize companioning should be mindful of their own emotions and seek to adopt a learning stance. Collectively, these 11 tenets are summarized in table 1 and summarize Wolfelt's relationally-based companioning skillset.

\section{Table 1}

\section{Eleven Tenets of Companioning}

Respect disorder or confusion

Be present

Not lead, but work alongside

Not judge others, but acknowledge their struggle

Be alongside the individual without thinking you are responsible for finding a way to help

Be mindful of one's own emotions

Be comfortable in silence

Not feel the need to progress, but be comfortable remaining in one place

Learn from others

Be curious rather than act as an expert

Honor the individual's spirit

\section{Companioning in Supervision}

Applying the concept of companioning to counselor supervision would be a unique approach that brings together many important supervision skills and benefits supervisors. This skillset is counter to some supervisors who operate as if they are in 
front of their supervisees leading them or behind their supervisees propelling them towards growth. Still other supervisors take a "hands-off" approach, while others micromanage (Iedema et al., 2010). Supervisors who employ companioning seek to meet supervisees where they are at, come alongside them, and accompany them through growing moments in their clinical experiences. Supervisors can intentionally offer supervisees a safe place where they can authentically share these professional concerns (Christensen \& Kline, 2001). Wolfelt (2005) noted that companioning is "not about assessing, analyzing, fixing or resolving" another individual's concerns, but it is "about being totally present" for that individual (p. 17). Therefore, instead of being distracted or rushing to fix the problem as a supervisee presents a concern (Enyedy et al., 2003), a supervisor strives to be present-oriented, to listen in a non-judgmental way, to honor the individual supervisee, and to be comfortable when silence enters the supervision space. The supervisor inwardly self-reflects on the supervision topic, does not rush, and allows for a spirit of curiosity. As a result of companioning, supervisees can come to their own resolution of concerns, gain a sense of mastery in counseling, feel empowered, and grow through the supervision experience. These elements, such as empowerment (Cook et al., 2018), are vitally important.

The application of companioning skills would also benefit supervisees. Supervisees encounter many concerns in their counseling work (Barnett \& Molzon, 2014), such as boundary issues (Scarborough et al., 2006), the reception of feedback (Hoffman et al., 2005), confidentiality (Pope \& Vetter, 1992), and anxiety related to competency (Harvey \& Struzziero, 2008), among others. Rønnestad and Skovholt (2003) showcased that supervisees face professional challenges not only as novice counselors, but also as they develop throughout their counseling career. As supervisees experience the companioning skillset in supervision, they could then have a type of supervision that would work for them, provide a space to share possible concerns without fear of judgement, and be able to work through professional concerns they are experiencing with clients.

Furthermore, the companioning skillset could benefit the supervisor-supervisee relationship. An additional challenge to those listed above is experienced in supervision 
when supervisees present with resistance (Liddle, 1986; Masters, 1992). Resistant behaviors may include seeking answers excessively from the supervisor, avoiding talk related to counseling skills, appearing overly fragile to avoid talking about issues, seeming helpless, blaming concerns on external factors (Bauman, 1972), engaging in power struggles with supervisors, missing supervision sessions consistently, and being noncompliant with tasks (Bernard \& Goodyear, 2014). This set of skills can be utilized in supervision to help overcome such resistance and guide the supervision process towards a positive outcome. For instance, instead of meeting the resistance of the supervisee headon, as some supervisors attempt (Grant \& Schofield, 2012), a supervisor using companioning would adopt a non-judgmental stance, remain in the resistance with the supervisee to work through it, respect the disorder that resistance can bring, and treat it as a professional learning moment. Working through this resistance can be difficult and vulnerable for both supervisor and supervisee. Johnson (2007) wrote that, "transformational supervisors see themselves as deliberately partnering with supervisees to shepherd them safely through the vulnerable transitions and hurdles characteristic of practical training" (pp. 262-263). Companioning offers supervisors invaluable skills to help work through transitions and to successfully overcome resistance when it occurs.

Finally, there are further benefits related to companioning that pertain to the larger aspect of counseling. Supervisors utilizing companioning have the opportunity to model this skillset for supervisees. Supervisees can experience first-hand how helpful it is to have a supervisor work alongside them, as opposed to telling them what is to be done or not to be done. These supervisees then have a model of companioning, experience what it looks and feels like to companion, can identify benefits of companioning, and can enact this skillset with clients. Companioning then becomes not just skills that are additive to the supervision relationship, but can be transformational to the counselorclient relationship. Supervisees who have seen these skills collectively modeled by supervisors and who have implemented them in session may experience an increase in competency, which may continue to develop their professional identity (Goltz \& Smith, 2014). Although not appropriate in all supervisory contexts and counseling 
circumstances, some supervisees and supervisors would greatly benefit from the many attributes of companioning.

\section{Companioning Related to Other Supervision Models}

The skillset of companioning can be easily integrated into various approaches of supervision. Companioning would be a great addition to some forms of supervision, as some of these skills are not found in all approaches and models of supervision (Berger et al., 2003; Martin \& Cannon, 2010; Nauert, 2000). In fact, some approaches run counter to the tenets of companioning. For instance, supervisors using medical-models of supervision emphasize that supervisees assess, diagnose, and treat concerns in a way that evaluates symptomology, compartmentalizes complex conditions with prescriptive clinical labels, and indicates there is one right way to corrective treatment (Nauert, 2000). Managed-care supervision prioritizes productivity, paperwork, and short-term treatment (Peake et al., 2002) as supervisors help supervisees efficiently assess and treat a client's concerns with the least number of sessions possible (Berger et al., 2003). Companioning skills are removed from these approaches. It would behoove supervisors using these models to consider integrating companioning to allow for more collaboration, selfawareness, and expertise from the supervisee.

Beyond the above approaches, the companioning skillset could be added to other well-known models of supervision. The discrimination model of supervision was conceptualized as an atheoretical framework to aid new counseling supervisors in organizing supervision sessions around three foci (i.e., intervention, conceptualization, and personalization) and three supervisory roles (i.e., teacher, counselor, and consultant; Bernard \& Goodyear, 2014). Besides this model, the integrated developmental model (IDM) enables supervisors to view supervisees within one of four developmental levels ranging from supervisees with limited counseling experience to supervisees who have personalized their counseling skills across various domains (Stoltenberg \& McNeill, 1997). Companioning could be an additive skillset within both models. If a supervisor using the discrimination model is teaching an intervention that a supervisee is struggling 
to utilize in session, companioning would allow the supervisor to respect possible confusion, bear witness to the learning struggle, and work with the supervisee as he or she learns. As a supervisor operates from the IDM to examine critically the growth of the supervisee within each of the domain areas, a supervisor may have the tendency to rush a conversation, lead the supervisee along, be future-oriented towards new goals, or focus on expertise. The additive skill of companioning would allow a space for the supervisor using this model to be present within the supervision session, work alongside the supervisee in skill-acquisition, and express curiosity on how the process is going. Therefore, these well-known models of supervision are not replaced, but enriched through companioning skills.

\section{Relational Models of Supervision}

Other supervision models align closely, but not fully, to the skillset of companioning. Narrative supervision, extending from narrative counseling, allows a counselor to uncover a client's narrative story and assist in restorying the life narrative (White \& Epston, 1990). In supervision, narrative work emphasizes supervisees' stories about themselves as counselors (MacKay \& Brown, 2014), how they formulate the story of the client, and the collaboration that exists between supervisees and supervisor (Bob, 1999; Rousmaniere \& Ellis, 2013). This work is accomplished through a variety of techniques, including honoring the supervisee's own personal experiences, reremembering practices, and developing professional communities where the supervisee can share experiences (Shurts, 2015). Companioning skills align with narrative supervision through Wolfelt's (2005) emphasis on coming alongside the individual and being collaborative, rather than being hierarchical. Other tenets of companioning, such as honoring the individual, learning from others, not taking on the responsibility for finding answers, and being curious rather than an expert are all seen in narrative supervision (Neuger, 2015). Yet, companioning could still be an additive element to narrative supervision. Through adopting the skills of companioning, narrative supervisors would be reminded not to rush to re-storying supervisees' situations and to be comfortable not 
progressing. Supervisors can also utilize companioning as a reminder that disorder and confusion are sometimes a part of stories and they can acknowledge this fact with supervisees without judgement. Furthermore, during difficult parts of narratives, supervisors can utilize companioning to remain silent and be present alongside supervisees.

Another similar approach to companioning is feminist supervision, or the application of feminist theory to the structure and process of supervision (Degges-White et al., 2013). Although Fickling and Tangen (2017) noted a lack of consensus on the approach of feminist supervision, other researchers identified the collaborative relationship between supervisor and supervisee, empowerment of the supervisee, the supervisor's adoption of a non-expert stance, social justice and advocacy, and a strengthbased approached as hallmarks of feminist supervision (Degges-White et al., 2013; Mangione et al., 2011; Nelson et al., 2006). This model aligns with the skills of companioning through its supervisor-supervisee collaboration, lack of judgment between the two professionals, acknowledgement of struggles, learning from others, and sense of curiosity. Yet, feminist supervision could also be strengthened by adding additional companioning skills. Companioning's tenets of respecting disorder and confusion, not feeling the need to progress in action, and being comfortable in silence would enhance supervision offered by feminist supervisors. Instead of trying to quickly fix social concerns impacting the work of the supervisee, supervisors enacting companioning may see a benefit in silently sitting in possible disorder, not feeling the need to work through it quickly, and merely being with the supervisee. These actions could have great positive effects for the supervisor-supervisee relationship.

Beyond narrative and feminist supervisors, the work of collaborative supervisors also has connection to the skills of companioning. Anderson (2002) described a collaborative supervision philosophy as "supervisees and supervisors developing relationships that invite jointly creating knowledge" (p. 1). Through this creation of knowledge, there is collaborative conversation between supervisors and supervisees, the hierarchical relationship is deemphasized, and supervisor and supervisee are both learner and teacher (Aducci \& Baptist, 2011; Anderson, 2002; MacKay \& Brown, 2013). The 
nature of collaborative supervision produces an environment where supervisee and supervisor respect and value what they each bring to the professional relationship (Aducci \& Baptist, 2011). Like other models, collaborative supervision aligns with some skills of companioning (e.g., collaborative, honoring of the individual, learning from others, etc.), but can also be strengthened through the application of other companioning skills. Supervisors would be reminded through the skills of companioning that they should be mindful of their own emotions, are not responsible for finding ways to help, and can be comfortable remaining in one place without progress being witnessed in supervision. As with narrative and feminist approaches to supervision, companioning does not take the place of collaborative supervision, but adds additional skills that strengthens what is already developed. As no model fully embraces the all tenets found in companioning, this skillset is a much-needed addition to current forms of supervision.

\section{A Companioning Case Study}

A case study may be one of the best ways to view the significance of companioning and illustrate the application of its skills in supervision. This relevancy is important considering the various models of supervision that implement similar skills to companioning (Aducci \& Baptist, 2011; Degges-White et al., 2013). Furthermore, this case study illustrates how the skills of companioning fit into the overall process of supervision and how they can enhance the supervisor-supervisee relationship.

\section{Case Study}

Claire is a counselor who just saw a new client, Martina. Martina is a 65-year-old Caucasian female who came to counseling presenting with concerns because her husband is dying from cancer. The client has been married to her husband for 42 years and reported feeling very afraid and worried. She stated to Claire, "The doctors told me that he only has a few more months, and I just don't know what I'm going to do without him. I'm going to be so alone!" Claire is also a female in her mid-60s and this client's presenting concern triggered Claire's long-held fear of being alone. As the session progressed and Martina told more of her story, Claire's feelings of fear related to being 
alone increased. The session concluded, and Claire was left with the feeling that she was ineffective in the session due to her own feelings of fear.

Claire scheduled an immediate session with her supervisor and replayed the session with attention paid to her own increasing emotional struggle during the session. As she identified so much with the client, she was aware of feeling hopelessness. She concluded her review with the statement, "I don't know what to say or what to do in session to help this client. I think whatever it is, I might need the same help."

The supervisor, Curtis, decides to rely on companioning skills to assist Claire in supervision. After hearing about the counseling session, he states, "This case is really difficult for you to sit with, as it seems to mirror some of your own fears. I can tell how much you care for this client and are worried about this situation." He gives Claire an opportunity to respond to these statements and then proceeds to question, "How can I best support you in your tremendous work with her?" Claire responds that she just needs to "work out" these feelings so she can best support her client. The supervisor senses that she might be looking for "the" answer, so he responds with, "I give you so much credit for holding space for a case that is so deeply activating for you. It must have been hard to remain in the entire session. How can you stay present with her and hold her pain with her, without trying to take it away?" His statement begins to comfort Claire, allows her not to feel judged, and his question begins to prompt her own thoughts about the client and the session.

Curtis recognizes the traction that the conversation is beginning to take, starts to feel a sense of relief that a solution will be coming, and internally notes his own feelings during the conversation. During the discussion, Claire begins to focus on her own loneliness and becomes quite tearful. Curtis does not say anything for several minutes and lets Claire have this time as an outlet for her emotions. She soon collects herself and tells Curtis she has recently been reading a book about grief and loss that has a few techniques she might be able to introduce within the session. The supervisor focuses on one of the techniques and interjects by stating, "Teach me how you might do this one." As Claire begins to develop some confidence in her ability to work with Martina through this demonstration, Curtis offers, "It feels like in some ways you are the perfect person to 
work with her, as you understand her fears and you care deeply. I wonder if that can be enough for both of you." Claire's additional comments to these remarks indicate that she is feeling more empowered to work with the client and her supervisor responds with, "It does seem that you have so much to offer her."

Claire finishes the conversation by saying, "Wow, I feel so much better. It really helps that you believe I can do this work. I sometimes wonder if I should have more training as a counselor or even if I am effective, but you are reminding me that it is not my job to fix this, nor can I. I so appreciate you hearing me and your support. I can feel what it is like to have someone alongside me. I'm going to continue seeing this client." Based upon this exchange, Curtis decides to monitor the supervisee's work with this client, considers referring her to seek her own counseling, and develops plans to integrate a self-care conversation during the next supervision appointment.

\section{Case Study Analysis}

While this case study may seem to some like typical conversation between a supervisor and a supervisee, the supervisor has intentionally interwoven tenets of companioning throughout the supervision time. Table 2 highlights the tenets of companioning and how they were utilized by the supervisor in this case study.

\section{Table 2}

Case Study Example

\begin{tabular}{ll}
\hline $\begin{array}{l}\text { Tenet of } \\
\text { Companioning }\end{array}$ & $\begin{array}{l}\text { Supervisor's Statement } \\
\text { Respect disorder }\end{array}$ \\
$\begin{array}{l}\text { "Th confusion } \\
\text { of your own fears." The supervisor is letting the supervisee know that he is } \\
\text { seeing the confusion she is presenting with and is willing, respectfully, to } \\
\text { sit with her in this disorder. }\end{array}$
\end{tabular}


Be present

Not lead, but work alongside
"I can tell how much you care for this client and are worried about this situation." The supervisor displays that he is present by highlighting key facts that have been mentioned previously by the supervisee.

"How can I best support you in your tremendous work with her?" The supervisor is verbally queuing the supervisee into the idea that she will lead this discussion as he comes alongside to offer what she needs.

Not judge others, "I give you so much credit for holding space for a case that is so deeply but acknowledge activating for you. It must have been hard to remain in the entire session." their struggle Here, the supervisee acknowledges the struggles the supervisee faced within the session.

Be alongside the individual without thinking you are responsible for finding a way to help

Be mindful of one's own emotions

Be comfortable in silence
"How can you stay present with her and hold her pain with her, without trying to take it away?" The supervisor stays alongside the supervisee in the situation. The supervisee may be looking to the supervisor for "the" answer and the supervisor continues not to take on this responsibility.

Curtis notes his own feelings during the conversation. The supervisor is not only working with the supervisee on her concern, but is mindful about what he is feeling. This is part of the supervising process.

During an emotional point of the supervision session, Claire become tearful. The supervisor recognizes that this is an important release for the supervisee and sits in silence. 
Not feel the need The emotionally tearful time of the supervisee lasts for several minutes.

to progress, but Rather than rushing through this time to develop a solution or outcome, the be comfortable supervisor remains in this moment. He recognizes that this is what is remaining in one needed right now.

place

Learn from "Teach me how you might do this." The supervisor asks to learn from the others supervisee how a technique might be incorporated into future counseling sessions. This is a learning moment for the supervisor and can solidify elements for the supervisee. Therefore, both are actively learning.

Be curious rather "I wonder if that can be enough for both of you." By wondering aloud, the than act as an supervisor is not positioning himself as an expert, but rather is continuing expert to be curious with the supervisee. This prompts the supervisee's continued reflection as she drives the conversation.

Honor the "It does seem that you have so much to offer her." Honoring the individual's supervisee's spirit is a natural way to begin to conclude the supervision spirit session. The supervisor highlights what the supervisee has to offer to the client and she ends with a starkly different demeanor from the beginning of the session.

\section{Discussion and Implications}

Companioning offers many positive benefits that should not be overlooked in the multitude of supervision skills, approaches, and models (Carlson \& Erickson, 2001; Gingerich \& Eisengart, 2000; Shurts, 2015). At its core, companioning is a relationallyoriented skillset that can be incorporated into current models of supervision to allow supervisors to work collaboratively alongside supervisees. Companioning can be started in a variety of ways. For instance, supervisors may share a little about companioning with 
supervisees, possible benefits, and why they are choosing to implement it in supervision. The supervisor could then utilize companioning and its 11 tenets (Wolfelt, 2005) within the course of supervision. As a supervisor seeks to be present, honor the supervisee's individual spirit, be curious, and employ the other tenets of this skillset, the professional relationship between the supervisor and the supervisee would be strengthened. As noted previously, the companioning skillet is distinct from current models of supervision, can be an additive to current practices, and has the potential to increase the relational quality of supervision.

As noted previously, supervisees can face various dilemmas in their counseling work, including ethical concerns (Barnett \& Molzon, 2014), questions related to counselor-client boundaries (Scarborough et al., 2006), confidentiality (Pope \& Vetter, 1992), or anxiety related to their own competency (Harvey \& Struzziero, 2008), among other worries. As supervisors utilize companioning, they foster a professional space where they can come alongside supervisees and assist them through such concerns. Companioning would allow supervisors to empower supervisees' own decision-making abilities, highlight learning moments, and foster curiosity rather than dictating one "correct" answer. This opportunity to instill empowerment in the supervision relationship can be important (Cook et al., 2018). Thus, supervisees grow in their own awareness on how to handle dilemmas. Furthermore, the respect and collaborative nature associated with companioning would allow supervisees to feel more free to return to their supervisor later with other concerns. This is distinct from some supervision experiences where supervisees may feel incompetent after a supervision session or feel as if the supervisor is unapproachable when concerns arise.

Adopting the skillset of companioning can not only be of value to supervisees, but also benefit supervisors. The utilization of this skill can directly help supervisors release the need to be in charge of the supervision session. No longer are sessions controlled by the supervisor, but instead the supervisor comes alongside the supervisee to collaboratively construct this time. This collaboration has been highlighted as being very important in supervision (Rousmaniere \& Ellis, 2013). Supervisors using companioning may feel less pressure in session as they no longer need to deliver the "right" answers all 
the time. Companioning would allow the supervisor to slow down the pace of supervision, draw upon the strengths of the supervisee, and be curious in the supervision session. This skill could foster an atmosphere that is more empowering to both supervisees and supervisors, thus possibly curving professional burnout and turnover rates that supervisors are left to deal with professionally (Regan, 2013). These benefits make the skillset viable and exciting for supervisors seeking to enhance their work. The flexibility of companioning also allows it to fit with many existing approaches and models of supervision.

\section{Counselor Education}

As companioning is a new skillset within the counseling supervision literature, there are further implications regarding education and training. Counselor educators who are introduced to companioning could implement these skills in their supervision work with master's-level practicum and internship students. As these skills are taught and modeled in educational courses, students would then be able to include the skills of companioning with their own clients at various counseling sites. Additionally, integrating companioning could be seamless for counselor educators who teach doctoral-level courses dedicated to the practice of supervision.

Counselor educators could also employ creative techniques, which has been seen as helpful in educating counseling students (Crowe, 2011), when teaching companioning skills. For instance, the educator could either provide a case study or ask students for a current concern, question, or situation that is occurring with a client. The counselor educator could then engage the students in a creative role play around that concern or case study. Different students could role play supervision from different models (e.g., narrative model, feminist model, collaborative model, discrimination model, and/or IDM) while incorporating companioning skills. As researchers have underscored that skills are often better understood and integrated into practice when demonstrated through experiential learning (Grant, 2006; Griffith \& Frieden, 2000; Kolb, 1984; Warren et al., 2012) this could be a great way to teach this skillset. 


\section{Further Research}

The companioning skillset is conceptual in nature and while it has been utilized by both authors, formal research has not been conducted. Future qualitative research could be conducted through phenomenological interviews to better understand the experience of incorporating companioning into supervision. It would be beneficial for researchers to gain the experience of companioning from both the supervisor's and the supervisee's perspective. A narrative analysis could illuminate what specific instances of

companioning look like between supervisors and supervisees. Quantitative research could also be utilized to explore this skill by collecting survey data on the effectiveness of companioning. Researchers utilizing questionnaires could ask supervisors to remark on the idea of companioning in general, as well as reflect on its specific tenets and the utilization of these in supervision. This future research could help solidify companioning as a needed skillset within the professional practice of counselor supervision and possibly further distinguish it as a skillset apart from models of supervision that are somewhat similar.

\section{Conclusion}

Counseling supervision is an essential professional practice conducted to ensure a client's welfare and the professional development of supervisees (Overholser, 2004). Yet, there is not one "right" way of conducting supervision, as is evident from the various models of supervision that exist (Anderson, 2002; Degges-White et al., 2013; MacKay \& Brown, 2014). As new models of supervision continue to be developed, so too can new skills related to counselor supervision be developed to strengthen existing models within the field of counselor supervision. Although the skillset of companioning may be similar to some supervision models (e.g., feminist supervision, narrative supervision, collaborative supervision), its 11 tenets offers unique considerations that make it an enriching addition to current modes of supervision. Therefore, supervisors are highly 
encouraged to adopt and integrate companioning as a skill into their modality of supervision. 


\section{References}

Aducci, C. J., \& Baptist, J. A. (2011). A collaborative-affirming approach to supervisory practice. Journal of Feminist Family Therapy, 23(2), 88-102. https://doi.org/10.1080/08952833.2011.574536

Anderson, H. (2002). Supervision as a collaborative community. Music Therapy Today (online). Music Therapy World. http://www.wfmt.info/Musictherapyworld/modules/mmmagazine/issues/2002061 3094600/20020613101715/Harlene.pdf

Barnett, J. E., \& Molzon, C. H. (2014). Clinical supervision of psychotherapy: Essential ethics issues for supervisors and supervisees. Journal of Clinical Psychology, 70(11), $1051-1061$.

http://jcu.ohionet.org/login?url=http://search.ebscohost.com/login.aspx?direct=tru e\&db=psyh\&AN=2014-43812-004\&site=ehost-live

Bauman, W. F. (1972). Games counselor trainees play: Dealing with trainee resistance. Counselor Education and Supervision, 11(4), 251-256. https://doi.org/10.1002/j.1556-6978.1972.tb01519.x

Berger, C. S., Robbins, C., Lewis, M., Mizrahi, T., \& Fleit, S. (2003). The impact of organizational change on social work staffing in a hospital setting: A national, longitudinal study of social work in hospitals. Social Work in Health Care, 37(1), 1-18. https://doi.org/10.1300/J010v37n01_01

Bernard, J. M. (1997). The discrimination model. In C. E. Watkins (Ed.), Handbook of psychotherapy supervision (pp. 310-327). Wiley. 
Bernard, J. M., \& Goodyear, R. K. (2014). Fundamentals in clinical supervision (5th ed.). Pearson.

Bob, S. R. (1999). Narrative approaches to supervision and case formulation. Psychotherapy: Theory, Research, Practice, Training, 36(2), 146-153. https://doi.org/10.1037/h0087641

Carlson, T. D., \& Erickson, M. J. (2001). Honoring and privileging personal experience and knowledge: Ideas for a narrative therapy approach to the training and supervision of new therapists. Contemporary Family Therapy, 23(2), 199-220. https://doi.org/10.1023/A:1011150303280

Christensen, T. M., \& Kline, W. B. (2001) Anxiety as a condition for learning in group supervision. Journal for Specialists in Group Work, 26(4), 385-396. https://doi.org/10.1080/01933920108413786

Cook, R. M., William, B. M., \& Wind, S. A. (2018). Supervisee perception of power in clinical supervision: The power dynamics in supervision scale. Training and Education in Professional Psychology, 12(3), 188-195. https://doi 10.1037/tep0000201.

Crowe, A. (2011). Teaching a course on creativity in counseling: Ideas for counselor educators. Journal of Creativity in Mental Health, 6(2), 149-165. doi: $10.1080 / 15401383.2011 .579875$

Degges-White, S. E., Colon, B. R., \& Borzumato-Gainey, C. (2013). Counseling supervision within a feminist framework: Guidelines for intervention. Journal of Humanistic Counseling, 52(1), 92-105. https://doi.org/10.1002/j.21611939.2013.00035.x 
Enyedy, K. C., Arcinue, F., Puri, N. N., Carter, J. W., Goodyear, R. K., \& Getzelman, M. A. (2003). Hindering phenomena in group supervision: Implications for practice. Professional Psychology: Research and Practice, 34(3), 312-317. https://doi.org/10.1037/0735-7028.34.3.312

Fickling, M. J., \& Tangen, J. L. (2017). A journey toward feminist supervision: A dual authoethnographic inquiry. The Journal of Counselor Preparation and Supervision, 9(2), http://dx.doi.org/10.7729/92.1219

Gingerich, W., \& Eisengart, S. (2000). Solution-focused brief therapy: A review of the outcome research. Family Process, 39(4), 477. https://doi.org/10.1111/j.15455300.2000.39408.x

Grant, J. (2006). Training counselors to work with complex clients: Enhancing emotional responsiveness through experiential methods. Counselor Education and Supervision, 45(3), 218-230. https://doi.org/10.1002/j.1556-6978.2006.tb00144.x

Grant, J., \& Schofield, M. J. (2012). Managing difficulties in supervision: Supervisors' perspectives. Journal of Counseling Psychology, 59(4); 528-541. https://doi.org/10.1037/a0030000

Griffith, B. A., \& Frieden, G. (2000). Facilitating reflective thinking in counselor education. Counselor Education and Supervision, 40(2), 82-93. https://doi.org/10.1002/j.15566978.2000.tb01240.x

Goltz, H. H., \& Smith, M. L. (2014). Forming and developing your professional identity: Easy as PI, Health Promotion Practice, 15(6), 1-5, https://doi.org/10.1177/1524839914541279 
Harvey, V. S., \& Struzziero, J.A. (2008). Professional development and supervision of school psychologists: From intern to expert (2nd ed.). Corwin/NASP Press.

Hoffman, M. A., Hill, C. E., Holmes, S. E., \& Freitas, G. F. (2005). Supervisor perspective on the process and outcome of giving easy, difficult, or no feedback to supervisees. Journal of Counseling Psychology, 52(1), 3-13. https://doi.org/10.1037/0022-0167.52.1.3

Iedema, R., Brownhill, S., Haines, M., Lancashire, B., Shaw, T., \& Street, J. (2010). Hands on, hands off: A model of clinical supervision that recognizes trainees need for support and independence. Australian Health Review: A Publication of the Australian Hospital Association, 34(3), 286-91. doi:10.1071/AH09773.

Johnson, W. B. (2007). Transformational supervision: When supervisors mentor. Professional Psychology: Research and Practice, 38(3), 259-267. https://doi.org/10.1037/0735-7028.38.3.259

Kolb, D. A. (1984). Experiential learning: Experience as the source of learning and development. Prentice Hall.

Liddle, B. (1986). Resistance in supervision: A response to perceived threat. Counselor Education and Supervision, 26(2), 117-127. https://doi.org/10.1002/j.15566978.1986.tb00706.x

MacKay, L., \& Brown, J. (2014). Collaborative approaches to family systems supervision: Differentiation of self. Australian and New Zealand Journal of Family Therapy, 34(4), 325-337. https://doi.org/10.1002/anzf.1036

Mangione, L., Mears, G., Vincent, W., \& Hawes, S. (2011). The supervisory relationship when women supervise women: An exploratory study of power, reflexivity, 
collaboration, and authenticity. The Clinical Supervisor, 30(2), 141-171.

https://doi.org/10.1080/07325223.2011.604272

Martin, F. A., \& Cannon, W. C. (2010). The necessity of a philosophy of clinical supervision. Counseling Outfitters. http://counselingoutfitters.com/vistas/vistas10/Article_45.pdf

Masters, M. A. (1992). The use of positive reframing in the context of supervision. Journal of Counseling \& Development, 70(3), 387-390. https://doi.org/10.1002/j.1556-6676.1992.tb01621.x

Nauert, R. C. (2000). The new millennium: Health care evolution in the 21st century. The Journal of Health Care Finance, 26(3), 1-13. https://www.ncbi.nlm.nih.gov/pubmed/10728481

Nelson, M. L., Gizara, S., Hope, A. C., Phelps, R., Steward, R., \& Weitzman, L. (2006). A feminist multicultural perspective on supervision. Journal of Multicultural Counseling \& Development, 34(2), 105-115. https://doi.org/10.1002/j.21611912.2006.tb00031.x

Neuger, C.C. (2015). Narrative therapy and supervision. Reflective Practice: Formation and Supervision in Ministry. http://journals.sfu.ca/rpfs/index.php/rpfs/article/viewFile/382/374, 27.02.2018

Overholser, J. C. (2004). The four pillars of psychotherapy supervision. The Clinical Supervisor, 23(1), 1-13. https://doi.org/10.1300/J001v23n01_01

Peake, T. H., Nussbaum, B. D., Tindell, S. D., \& Silverman, W. H. (2002). Clinical and counselling supervision references: Trends and needs. Psychotherapy: Theory, 
Research, Practice, Training, 39(1), 114-125. https://doi.org/10.1037/00333204.39.1.114

Pope, K. S., \& Vetter, V. A. (1992). Ethical dilemmas encountered by members of the American Psychology Association: A national survey. American Psychologist, 47(3), 397-411. http://dx.doi.org/10.1037/0003-066X.47.3.397

Regan, A. (2013). Counselor burnout and self-care within an outpatient mental health agency. [Master's thesis, The College at Brockport: State University of New York]. https://digitalcommons.brockport.edu/cgi/viewcontent.cgi?article=1143\&context= edc_theses

Rønnestad, M. H. \& Skovholt, T. M. (2003). The journey of the counselor and therapist: Research findings and perspectives on professional development. Journal of Career Development, 30(1), 5-44. https://doi.org/10.1023/A:1025173508081

Rousmaniere, T. G., \& Ellis, M. V. (2013, October 14). Developing the construct and measure of collaborative clinical supervision: The supervisee's perspective. Training and Education in Professional Psychology, 7(4), 300-308. doi: $10.1037 / \mathrm{a} 0033796$

Scarborough, J. L., Bernard, J. M., \& Morse, R. E. (2006). Boundary considerations between doctoral students and master's students. Counseling and Values, 51(1), 53-65. https://doi.org/10.1002/j.2161-007X.2006.tb00065.x

Shurts, W.M. (2015). Infusing postmodernism into counseling supervision: Challenges and recommendations. Journal of Counselor Preparation and Supervision, 7(3), 111-132. http://dx.doi.org/10.7729/73.1134 
Stoltenberg, C. D., \& McNeill, B. W. (1997). Clinical supervision from a developmental perspective: Research and practice. In C. E. Watkins Jr. (Ed.), Handbook of psychotherapy supervision. (pp. 184-202). John Wiley \& Sons Inc.

Warren, J., Hof, K., McGriff, D., \& Morris, L. B. (2012). Five experiential learning activities in addictions education. Journal of Creativity in Mental Health, 7(3), 273-288. https://doi.org/10.1080/15401383.2012.710172

White, M., \& Epston, D. (1990). Narrative means to therapeutic ends. Norton. 
